\title{
Grammar Jam: Adding a Creative Editing Tactic
}

\author{
David Gillespie*
}

February 20, 2018

\begin{abstract}
The author argues reading, hearing, and then composing musical lyrics involving grammatical concerns can help college writing students to edit more effectively for a song's grammar topic. Explaining that the songs need to offer specific advice, such as how to both spot and correct the grammatical problem, the writer offers lyrical examples and provides scholarly evidence for this approach. The essay explains what Grammar Jam is, why music can work, and how to use the tactic in the classroom.
\end{abstract}

As a Faculty Tutor in my university's writing center for over twenty years, I hear this student response repeatedly when a person comes in for tutoring: "I just want my paper to flow better and to fix the errors." However, these students rarely label a specific "error" to fix, and they lack tactics for improving the "flow." They lack the knowledge about grammar, syntax, style, and usage that they need in order to name and correct certain weaknesses in their writing. As a tutor, I can focus directly on a student's grammatical needs (i.e., concise, coherent, correct sentencing) one-on-one, but as a teacher, I cannot devote that same attention to each student during class. In class, different approaches to grammar study are needed, and I call one of them Grammar Jam. Music - specifically, reading and hearing lyrics involving grammatical concerns and then creating verses to their own chosen songs - can help college writing students to edit more effectively for their song's grammar issue, whether it be wordiness, sentence-combining needs, comma use, run-ons, or other issues. Both sides of this dual exercise, reading my models and then writing their own, offer a creative path toward a student's understanding of important grammatical issues, but the act of composing their own songs is especially necessary because it focuses on the individual's specific sentencing need.

\footnotetext{
*Department of Writing Studies, Rhetoric, and Composition, Roger Williams University. dgillespie@rwu.edu. Copyright 2018 David Gillespie. This work is licensed under a Creative Commons Attribution-NonCommercial 4.0 International License (http://creativecommons.org/licenses/bync/4.0/).

${ }^{\dagger}$ Submitted, 3/14/2017; Accepted, 11/2/2017.
} 


\section{What Grammar Jam Is}

At its core, Grammar Jam is simply a mnemonic device for strengthening the editing process - a creative extra step, a reminder, with specific tips concerning a problematic pattern. As an illustration, check these two short verses and try to hear the melody:

If you add a weak verb to your statement

Like "is" and "are" and "was" and "were"

Rephrase to make a statement. Edit "to be."

Just circle the "is" or "are," the bland word

And ask this question concisely

Who or what does what? Edit "to be."

Most readers from the baby boomer generation (or any Beatles' fan from any generation) would have turned "Edit 'to be" " into "Let it Be" by the Beatles, for that is the intended melody. Most of my students still know the Beatles, along with nearly all the "songs" I have created for them since introducing Grammar Jam in class over a decade ago.

Cyberspace offers thousands of songs about grammar, so why is Grammar Jam different? Just compare my "song" above to any in a Google search for "Wordiness Song," for example. While the endless links of melodies offer fairly useless lyrical advice (mainly just repeating the word "wordy"), my lyrics cover not only what to look for (e.g., weak verbs such as "is"), but also how to fix a problem, such as applying the who-does-what question. I encourage students to use my specific tips and even actual words/lines when they build their own songs because I want their verses to be as helpful and memorable as possible. I want students to remember their song's topic so that they will more likely edit for that problem after building and revising a paragraph or a whole paper.

Researchers have designated "three features of successful mnemonic devices: (1) they create a structure for learning, (2) they provide a distinctive memory record so that the material is not easily forgotten, and (3) they guide the reader in the retrieval process" (Ashcroft, 2002 as cited in Rainey \& Larsen, 2002, p. 177). Grammar Jam fits all three criteria - the "structure" of the songs, the "memory" of the melodies, and the "guidance" of the lyrics. My songs, as well as those that my students are asked to write for this assignment, offer advice on how to spot a specific editing problem and how to fix it, as illustrated in my "Edit 'to Be" lyrics above. Consider this second example, a more modern song, one that many of my first-year college students seem to know:

If you start a sentence with "By _ing"

Follow with the doer of that thing

Or you'll create a modifier that is dangling. 
That quick stanza is based on Mumford and Sons' "The Cave"-hear it? Note how this short example works: The first line shows how to find the potential error (scan for "By _ing" sentence beginnings), the second suggests how to fix it (follow with the doer), and the third line covers why. The pleasing melody makes the information more memorable. As summed up by Rainey and Larsen (2002), "the rhythm and melody of a familiar song could provide a structure for learning unfamiliar information" (p. 177), and they believe that "it seems likely that familiar music will provide more of a mnemonic effect" (p. 185), and suggest that others explore that hypothesis. The key term in both conclusions is "familiar," for with Grammar Jam, students choose their favorite songs and add the unfamiliar (the grammar topic's rules) to them.

Besides requiring reading and writing grammar lyrics, the Grammar Jam exercise contains other beneficial elements. Clearly, singing is an important and fun component of the exercise because students not only hear and see the editing advice and specific examples, but also enjoy watching their teacher make a bit of a fool of himself by singing. (They almost always applaud afterwards.) Even when I request they sing their own compositions in groups, they usually overcome embarrassment and do so, again to applause. The exercise also provides a layered approach to strengthening editing skills. In "Grouping Students to Teach Grammar," Breznak and Scott (2003) state, "it takes multiple exposures of a concept to reinforce learning" (p. 59). With a good Grammar Jam in-class exercise, a teacher can bundle those exposures: the teacher's lyrics, the traditional example, the students' verse(s) - three different ways of looking at a single grammatical issue. Even a song required for homework offers two approaches, one through studying the issue (see the instructional slides provided as "supplementary materials") and the other through creating the lyrics for a chosen song. And since students choose their own song topics, meta-cognition occurs since they must analyze their main editing needs, thus offering an individual, student-centered angle to Grammar Jam. In other words, when their paragraphs require editing, students will more likely check for that grammatical problem because they have already determined it and written creatively about the issue.

\section{Why to Add Music to the Editing Process}

Grammar Jam is enjoyable (most of you have probably smiled over my two songs, maybe even sung them aloud), and having fun, by itself, helps to create a learning atmosphere. However, look at the exercise pedagogically, considering the discourse community our students are trying to reach. When writing papers, college students converse in an academic discourse community, an audience which has high expectations not only for the content, but also for its delivery. In fact, a grammatical problem sends academic readers at least one of two ethos-damaging messages: The student does not know about the issue (unskilled) or is not worried about the problem (uncaring). However, students need to care because, as Feed and Broadhead (1987) remind us, students "are writers whose processes and products are substantially affected by discourse communities that elicit and shape their utterance" (p. 164). In short, academic audiences not only expect 
certain standards, but also push ("elicit and shape") students to adopt them.

Does such pressure mean that composition instructors must spend extensive class time focused on grammar? Writing professionals know that grammatical errors represent just a part of the writing process. Indeed, correcting grammar errors is just a part of the editing process, which includes not only dangling modifiers, but also non-error issues like wordiness and choppy phrasing - i.e., any sentencing concern that interrupts the flow of communication between writer and reader. In other words, like any other teaching tactic, Grammar Jam should not be overused; instead, it should be employed as one exercise toward improving a student's sentencing control. And it can be lasting; Rainey and Larsen's (2002) experiments on remembering lists of people's names have suggested "that the musical presentation would result in better long-term memory than the spoken presentation" (p. 184). That long-term effect is required for a transfer of skills to future papers, the goal of every writing teacher.

But can simple song lyrics help students to overcome embedded problematic patterns, such as overusing weak verbs and scattering run-ons through their paragraphs? While Grammar Jam offers just one way to tackle editing problems, the exercise provides particular benefits. Most superficially, the songs are entertaining. But the exercise also leads to collaboration and teamwork - including important social and academic skills. Individually, the lyrics focus students on editing problems that need their conscious attention since the catchy lyrics (especially those chosen by students themselves) continually remind the writer to edit for that specific problem.

Several examples from a variety of fields suggest that the right song lyrics can assist learning. A University of Pennsylvania professor used lyrics about diseases to teach her pre-med students (Kadaba, 2001 as cited in Knabb, 2003). A British doctor, Tapas Mukherjee of Glenfield Hospital in Leicester, created a song about hospital guidelines involving asthma patients in hopes of increasing his colleagues' adherence to those rules (Paul, 2013). A cognitive scientist, David Rubin showed that college students remembered ballads more often when the lyrics were rhymed (Paul, 2013). Finally, an experiment focused on learning a new language, Hungarian, proved "that singing can facilitate short-term paired-associate phrase learning in an unfamiliar language" (Ludke, Ferreira, \& Overy, 2014, p. 41). These illustrations focus on medical and language knowledge, the key being that the lyrics helped students to remember terms and meanings. That same topical memory can be related to grammatical problems, to what they are and how they can be corrected.

Like any tool, Grammar Jam will be picked up by some students more than by others; yet, all of them will use it. I have never had a single alienated-looking student during any in-class Grammar Jam work, as suggested by their more open body language and engagement with the songs and their peers. Even introverted students who do not converse well with others seem drawn in by the creative process, sharing verses and revising them for presentation. As Breznak and Scott (2003) contend, "students enjoy working with their peers in small groups. ... In a safe learning environment (i.e., one with 
no anticipated criticism), students don't fear presenting in front of their peers" (p. 59). With Grammar Jam's collaborative and positive atmosphere, students' body language is open (more huddled grouping, more focus, no crossed arms), group work spirited (shared opinions and laughter), cell phones absent - unless students are connecting to YouTube to find the melodies for chosen songs, a step that I encourage. Most students even sing their songs in groups to the entire class, although that is not required. Peers support each other's efforts with laughter and applause.

Of course, not all teachers can sing well. But voice quality is no prerequisite to singing, and a writing instructor will need to warble a bit to model Grammar Jam. Keep these points in mind: The stanzas are fairly short, and the worse a teacher sings, the more his or her students will enjoy the performance.

\section{How to Create and Incorporate Grammar Jam}

To the students' actual creation of Grammar Jam stanzas, I devote only two homework assignments and allocate parts of just three (at the most) classes to the songs themselves (more on that later). Outside of class, I have students create stanzas for two grammatical areas - usually wordiness and common errors - and in class we build lyrics about punctuation. None of these Grammar Jam exercises occurs before mid-semester, either, because by then I have repeatedly identified each writer's grammatical patterns of error through my comments on their papers. As English professor and education writer James Lang (2016) states, "if we want students to remember something-facts, concepts, or skills - they must engage in frequent efforts to retrieve that material from memory" (p. 8). Due to time restraints in class, that frequency should take place mainly out of class, hopefully becoming a part of each student's editing process.

As with most good lessons, Grammar Jam begins in class with a model, so a teacher has to create some good lyrics (how to spot, how to fix) for a specific grammatical issue. While readers are welcome to employ my examples (consult supplementary materials for more examples of my songs), an instructor should think of favorite songs (classic rock for me) and consider other jingles, too, even Christmas carols or nursery rhymes, which work really well because of their well-known melodies. To illustrate again, I offer the first stanza from my longest song, "The Rules of Punctuation," with thanks to Simon and Garfunkel:

Semicolon, you don't bend

To use you, I must end

A statement and begin another

Perhaps with "therefore" or "however."

A soft period, you balance two main thoughts

Like a see-saw 
Or sometimes items in a complex list.

Hear "The Sounds of Silence"? If teachers put that stanza on the board (or screen) and sing it, they will encounter rows of smiling faces. More importantly, if a teacher or students put semicolon examples (from their current in-progress papers) on the board, they will see how the song can help them to locate faulty semicolons, ones that do not "balance" statements but instead divide a single statement - in my experience, about $75 \%$ of students' semicolons. The remaining stanzas of this song are available in supplementary materials, and I invite you to use my lyrics in your own classes.

From my semicolon stanza above (or even the full punctuation PowerPoint), an instructor could go in many pedagogical directions, but I might continue the class as follows:

1. Write a faulty semicolon sentence on the board and then use the lyrical advice to analyze the model.

2. Ask for volunteers to put their own current papers' semicolon examples on the board and use my lyrics to analyze them.

3. Have students form groups of three of four (just people around them), choose a different song, and create lyrics about semicolon use, using their own ideas and/or my model's specific tips, such as my "balancing" point about semicolons. Alternately, I might have the groups choose another punctuation mark and have them create more "The Rules of Punctuation" stanzas to follow my semicolon one.

4. Present their songs to the class.

If I had students read my "The Rules of Punctuation" PowerPoint for homework, I would ask them to choose the most problematic punctuation mark for them and then to incorporate my lyrics (and their own) into their own chosen song. Then, in class, I would have them share their songs and perhaps go through some of the steps above, especially item 2 because whenever possible I relate work to the student's own writing. About learning, Hwu and Sun (2012) state, "it is plausible that the memory for meaningful material and connected text [... ] has a facilitative effect on the learning of explicit grammar rules" (p. 507), the key to their studies being the adjectives "meaningful" and "connected," two crucial aspects of knowledge acquisition. Grammar Jam songs are meaningful when students choose their individual problematic sentencing issue and create their own lyrics, which build a connection between the melody and the grammar content.

What about the quality of the students' songs? Can students create effective lyrics? Through direct classroom observation, I have noticed that most groups follow a leader, but that does not mean that one person does all the work, because all the members participate. I promote students becoming teachers by sharing opinions and debating, and the Grammar Jam exercise does so without my intervention. Also, the songs are easier to create if students borrow some of my lyrics' tips and examples and then adapt them to their chosen melodies (a tactic I stress). In adapting my lyrics, the class needs no lyric-writing advice. I do not take the time to offer such guidance, though some teachers 
might use this as an opportunity to teach the genre of musical lyrics. Grammar Jam mainly requires rhyming, and the group work helps because three or four minds can find a rhyme more easily than one. The students also fit the syllables into the melodies fairly easily; usually, one student per group is stronger at matching words to melodies, so he or she becomes the teacher, as mentioned above. As I walk around the groups, dipping in to monitor work and offer suggestions, I notice the collaborative efforts. No individuals are left on the periphery of the groups.

What about assessment? How do I know that Grammar Jam works? Admittedly, I do no pre- and post-testing for grammar, mainly because I devote most of my class time to issues at the paragraph level of structure such as how to analyze, summarize, paraphrase, generate, organize, focus, develop, and revise ideas to build manageable and communicable blocks of information. With grammar, I use their papers to explain each individual's problematic patterns, and in a Sentencing Checklist (of common problems), I offer the same sorts of information (what to look for, how to fix) that I add to my Grammar Jam models. To use a cliché, I lead them to the water, but I cannot force them to drink it. However, the Grammar Jam exercises at least make the individual student consider his or her specific editing needs, a crucial self-reflection step. Also, if the student's original song lyrics are effective, then a teacher can assess the individual's understanding of a concept, such as run-ons. Such knowledge is required for students to transfer sentencing skills to future papers.

Lyrics do not have to be restricted just to grammar, either, and a teacher's models and students' songs could focus on other composition terms and problems (even about subject-matter knowledge from other fields). To strengthen writing skills, specifically, students need knowledge involving composition, rhetoric, and even other mnemonic devices such as a professor's acronyms. For instance, consider citation formats: Since many students have trouble incorporating quotations into paragraphs, I created the acronym ICE-Introduce, Cite, Explain (an idea I have since spotted in other texts) - but perhaps I should also build a stanza. Paul McCartney could help: "MLA, the most common college format today. Use the name up front and then the page, ..."

OK, "Yesterday" and I have gotten this "Jam" started; now finish the stanza (just one more line), show it to students, and sing.

\section{The assignment}

See the Supplementary Files for this article at thepromptjournal.com for a PDF facsimile of the original formatting of this assignment.

Assignment Prompt: Think of your grammatical nemesis - is it comma use, wordiness, run-ons, etc.? Now choose a well-known song melody (your favorite song, a Christmas carol, even a nursery rhyme) and add lyrics about your grammatical obstacle. Be specific: 
offer lyrics that both identify and fix the problem. Feel free to use ideas (even whole lines) from my grammar PowerPoints and/or songs. (Note to Instructors: This prompt can be narrowed from overall "grammatical nemesis" to "the punctuation mark that gives you the most trouble" or to "your main grammatical error," etc.-i.e., to some specific grammatical area. This narrowing is suggested if a teacher uses Grammar Jam two or three times during the semester.)

\section{References}

Breznak, R. M., \& Scott, J. (2003). Grouping students to teach grammar. Education Digest, 69(4), 58-61.

Freed, R. C., \& Broadhead, G. J. (1987). Discourse communities, sacred texts, and institutional norms. College Composition and Communication, 38(2), 154-165.

Hwu, F., \& Sun, S. (2012). The aptitude-treatment interaction effects on the learning of grammar rules. System, 40(4), 505-521. http://doi.org/10.1016/j.system.2012.10.009

Knabb, M. (2003). Rapping to review: A novel strategy to engage students and summarize course material. Advances in Physiology Education, 27(3), 157-159.

Lang, J. M. (2016, September). Small teaching: Everyday lessons from the science of learning. NEA Higher Education Advocate, 34(4), 6-9.

Ludke, K. M., Ferreira, F., \& Overy, K. (2014). Singing can facilitate foreign language learning. Memory \& Cognition, 42(1), 41-52.

Paul, A. M. (2013, September 22). How music can improve memory. Retrieved August 22, 2016, from https://ww2.kqed.org/mindshift/2013/09/22/how-music-can-improvememory/

Rainey, D. W., \& Larsen, J. D. (2002). The effect of familiar melodies on initial learning and long-term memory for unconnected text. Music Perception: An Interdisciplinary Journal, 20 (2), 173-186. http://doi.org/10.1525/mp.2002.20.2.173 